\title{
On the composition and neutrix composition of the delta function and powers of the inverse hyperbolic sine function
}

\begin{abstract}
Lets $\mathrm{F}$ be a distribution in $\mathrm{D}^{\prime}$ and let $\mathrm{f}$ be a locally summable function. The composition $\mathrm{F}(\mathrm{f}(\mathrm{x}))$ of $\mathrm{F}$ and $\mathrm{f}$ is said to exist and be equal to the distribution $\mathrm{h}(\mathrm{x})$ if the limit of the sequence $\{\mathrm{Fn}(\mathrm{f}(\mathrm{x}))\}$ is equal to $\mathrm{h}(\mathrm{x})$, where $\mathrm{Fn}(\mathrm{x})=\mathrm{F}(\mathrm{x}) * \delta \mathrm{n}(\mathrm{x})$ for $\mathrm{n}=1,2, \ldots$ and $\{\delta \mathrm{n}(\mathrm{x})\}$ is a certain regular sequence converging to the Dirac delta function. It is proved that the neutrix composition $\delta\left[\left(\sinh \mathrm{x}^{+}\right)\right]$exists and for $\mathrm{s}=0,1,2, \ldots$ and $\mathrm{r}=1,2, \ldots$, where $\mathrm{M}$ is the smallest integer greater than $(\mathrm{s}-\mathrm{r}+1) / \mathrm{r}$ and Further results are also proved.
\end{abstract}

Keyword: Distribution; Delta function; Composition of distributions; Neutrix; Neutrix limit; Neutrix composition of distributions; 33B10; 46F10 